\title{
NARRATIVAS SAGRADAS: AUTOBIOGRAFÍAS \\ ESPIRITUALES DE MUJERES COMO PRÁCTICA INTERCULTURAL
}

Sacred narratives: spiritual autobiographies of women as intercultural practice Narrativas sagradas: autobiografias de mulheres como prática intercultural

\author{
Rosa Persida Cheuquenao Aillapan ${ }^{1}$
}

Andrea de Lourdes Castillo Muñoz ${ }^{2}$

"Es difícil comprender nuestras vidas sin las biografías de los demás".

(Tsultrim Allione)

\begin{abstract}
Resumen
Se analizó el reconocimiento de la espiritualidad de las mujeres como un ámbito de negación y como un ejercicio que permitiría un diálogo interespiritual a través de las autobiografías de las autoras. A partir de antecedentes sobre el reconocimiento de la espiritualidad de las mujeres, se realizó una investigación cualitativa con diseño biográfico narrativo. Los resultados evidenciaron que el reconocimiento de dicha espiritualidad forma parte de una interculturalidad crítica y decolonial, así como que la autobiografía espiritual sería un instrumento de diálogo entre espiritualidades. Se concluye que la espiritualidad de la intemperie posibilitaría el proceso de reconocimiento intercultural.
\end{abstract}

Palabras claves: espiritualidades, reconocimiento, mujeres, interculturalidad, intemperie.

1 Mujer mapuche perteneciente a la Identidad Territorial Lafkenche, Chile. Correo electrónico: persidach@gmail.com

2 Universidad Católica de Temuco, Chile. Correo electrónico: relmurayen@gmail.com ORCID: https://orcid.org/0000-0001-7893-7651 


\begin{abstract}
The recognition of women's spirituality as a sphere of denial and as an exercise that would allow an interspiritual dialogue through the autobiographies of the authors was analyzed. Based on antecedents on the recognition of the spirituality of women, a qualitative research with a narrative biographical design was carried out. The results showed that the recognition of the spirituality of women is part of a critical and decolonial interculturality and that spiritual autobiography would be an instrument of dialogue between spiritualities. It is concluded that the spirituality of the outdoors would make the intercultural recognition process possible.
\end{abstract}

Keywords: spiritualities, recognition, women, interculturality, bad weather.

\begin{abstract}
Resumo
Analisou-se o reconhecimento da espiritualidade das mulheres como um âmbito de negação e como um exercício que permitiria um diálogo interespiritual através das autobiografias das autoras. A partir de antecedentes sobre o reconhecimento da espiritualidade das mulheres, realizou-se uma investigação qualitativa com desenho biográfico narrativo. Os resultados evidenciaram que o reconhecimento de dessa espiritualidade forma parte de uma interculturalidade crítica e decolonial, assim como que a autobiografia espiritual seria um instrumento de diálogo entre espiritualidades. Conclui-se que a espiritualidade da intempérie possibilitaria o processo de reconhecimento intercultural.
\end{abstract}

Palavras-chave: espiritualidades, reconhecimento, mulheres, interculturalidade, intempérie

\section{Introducción}

La espiritualidad forma parte, e incluso está a la base, del encuentro entre diferentes, siendo una práctica de reconocimiento y de convivencia valórica. La interculturalidad como proyecto exige abordar la experiencia espiritual o religiosa. El rol de la espiritualidad en el proyecto de la interculturalidad o diálogo - convivencia entre cosmovisiones diversas - requiere un verdadero encuentro o compartir entre las personas de culturas distintas, quienes pueden expresar el sentido profundo de lo que creen, lo cual es una condición de la dinámica del reconocimiento pleno del otro/a que ha tenido como eje la negación:

la patología de una historia cultural y social que ha normalizado teorías y prácticas de negación y de opresión del otro. Esta es la historia a cuya luz deben examinarse las posibilidades y límites de las teorías y las políticas del reconocimiento, para plantear desde esa contextualización histórica la pregunta incómoda de si la respuesta del 
reconocimiento paga tributo todavía a dicha historia. ${ }^{3}$

Ha habido una colonización de las espiritualidades dominantes que niega las cosmovisiones o espiritualidades indígenas, por lo que es necesario, entonces, asumir un férreo reconocimiento.

Nuestras biografías y ejemplos en diferentes ámbitos están marcados de rostros, acciones y nombres de hombres, así que la biografía de las mujeres es una práctica histórica constante de negación. En el ámbito de la espiritualidad, son los santos varones los faros luminosos o referentes ejemplares en la vida de las mujeres. Esto ha llevado a que sean pocas las referencias femeninas, sobre todo en el campo espiritual: "El tema de la espiritualidad en las mujeres está totalmente abierto, muchas de nosotras estamos investigando con el fin de descubrir cuál es realmente nuestro camino espiritual". ${ }^{4}$

El acto de narrarnos entre nosotras/os y hacia otras/os nos hace tocar la necesaria vulnerabilidad y confianza "producto de una época que insiste en mantener una división entre problemas privados y asuntos públicos, suponiendo

3 Raúl Fornet Betancourt, Transformación intercultural de la filosofia. (Barcelona: Desclée de Brouwer, 2001), 14.

4 Tsultrim Allione, Mujeres de sabiduría. (Barcelona: Ediciones La liebre de marzo, 2016), 4. un yo que tiene mucho que perder si muestra demasiadas emociones". ${ }^{5}$

En este contexto, el presente artículo indaga las espiritualidades de las mujeres, a través de sus biografías, para preguntarse: ¿Cómo se está viviendo el auto- y heterorreconocimiento espiritual? ¿Qué preguntas o afirmaciones, repensares y resentires están viviendo las mujeres en relación con la interculturalidad y a la(s) espiritualidad(es)? ¿Cómo descolonizar ${ }^{6}$ las espiritualidades? Creemos que abordar la temática de la espiritualidad es clave a la hora de hablar de reconocimiento, interculturalidad y descolonización. Iremos entre complejidades y complicidades, en un ejercicio que intenta acercarnos a ciertas respuestas y, además, sacarnos tanto de la soledad como de la individualidad de las autorías, con el afán de superar la colonialidad del ser y del saber. ${ }^{7}$

5 Marcela Bohórquez, "Brujas contemporáneas: entre mundos y devenires espirituales", Revista NÓMADAS 50 (2019): 142.

6 En acuerdo con los señalamientos de C. Walsh, la descolonización la entendemos como la generación de transformaciones estructurales que permiten nombrar las prácticas culturales como una totalidad superando la colonialidad, y cuestionan las relaciones de saber-poder para descolonizar el conocimiento y las relaciones o prácticas de dependencia (2005).

7 Nelson Maldonado, "Sobre la colonialidad del ser: contribuciones al desarrollo de un concepto". En: El giro decolonial. Reflexiones para una diversidad epistémica más allá del capitalismo global, editores Santiago Castro-Gómez y Ramón Grosfoguel (Bogotá: Lesco Pensar-Siglo del Hombre editores, 2007), 127-167.

Ramón Grosfoguel, "La descolonización de la economía política y los estudios postcoloniales. 
Los relatos que se examinan se registraron en tres momentos: 1) relato de las biografías por separado; 2) puesta en común de biografías; 3) consenso y desafíos. Con base en este material, el objetivo del estudio se centró en analizar el reconocimiento de la espiritualidad de las mujeres como un ámbito y práctica de negación histórica necesaria en un proceso intercultural.

\section{Witral}

Somos el witral ${ }^{8}$, es decir, todo el telar en general compuesto de nombres, lugares, personas y diversos paisajes, dibujos. Para disponer los ojos, el corazón, la mente, es necesario saber quién está al otro lado del texto, quién respira entre letra y letra. Nuestro desafío es que el lector/a sintonice con la vivencia espiritual de ambas mujeres: una mapuche con feyentun ${ }^{9}$ mapuche, católica y evangélica, y la otra mestiza, católica no practicante. La idea es que esa sintonía la haga con su propia biografía espiritual.

"Mi nombre es Rosa Persida Cheuquenao Aillapan, hija mayor de la

Transmodernidad, pensamiento fronterizo y colonialidad global", Tabula Rasa 4 (2006): 17-48.

8 En mapudungun, corresponde al conjunto del telar mapuche (estructura de madera, urdimbre y trama) que permite realizar la textilería de esta agrupación indígena, principalmente por las mujeres.

9 En mapudungun, corresponde a la acción de creer relacionada con el sistema de creencias. familia de don Manuel Segundo Cheuquenao Melillan y doña María Rosa Aillapan Antiman. Somos diez hermanos, tres fallecidos, cinco mujeres y tres hermanos hombres. Nacida y criada en la comuna de Teodoro Schmidt.

Hoy vivo en la comunidad Marcelo Travol- Llanka II, en la comuna de Loncoche, desde el 2008. Dieciséis años dirigente de comunidad. Madre soltera con dos hermosas hijas. Soy mujer mapuche, hablante muy apegada de mi identidad cultural, aferrada a la vida. Me gusta ser solidaria con actitud de humildad, cuyo propósito es entregar, aportar y ayudar a mis pares para el buen entendimiento de ambas culturas, porque Ngünechen ${ }^{10}$ nos ha creado y nos regala la vida, esta tierra, para ser parte y aporte necesario en esta sociedad.

Mi profesión es técnico agrícola y tengo varios estudios de capacitación en el ámbito social y organizacional, desde donde he vivenciado e indagado diferentes feyentun, para entender y conocer las miradas o la forma de

10 En mapudungun, proviene de dos vocablos: ngüne, que significa 'voluntad, raíz, origen $\mathrm{y}$ protector', y, che, que quiere decir 'hombre, personas o gente en general'. Comúnmente, se ha definido como "sostenedor, dejador y hacedor del mundo por voluntad propia y protector de la familia mapuche". Rodrigo Becerra y Gabriel Llanquinao, editores, Mapun kimün. Relaciones mapunche entre persona, tiempo y espacio. (Santiago: Ocho Libros, 2017): 92. 
ver la vida para una buena convivencia. Tengo amplia trayectoria en conocimiento del sentir de la vida de los distintos pueblos indígenas, en los niveles nacional e internacional. He trabajado en instituciones eclesiásticas, como también en las del Estado, donde nuestra vida como mapuches o nuestro modo de verla es invisibilizado, folclorizado, manipulado.

En mi experiencia como mujer mapuche, desde la infancia actué bajo el sistema de nuestro pueblo. Tuve que derribar muchas trabas psíquicas para ser lo que hoy soy; golpear mesas y sacrificar mi sentir para dejar precedente de que, como mujeres indígenas, somos capaces de hacer desarrollo en los diferentes ámbitos.

Fui dirigente desde los catorce años en mi comunidad, porque seguí las huellas de mi padre, acompañándole en los procesos dirigenciales que eran muy difíciles. Hoy soy facilitadora intercultural; para mí significa ser la mediadora de dos culturas, mediante lo cual transferimos, de persona a persona, historia, sabiduría, costumbres, valores, amor, respeto mutuo entre una y otra, sabiendo tomar el peso de las riquezas que hay en cada cultura, en este caso, de nuestro pueblo mapuche, lleno de sabiduría y basado en la reciprocidad."
"Soy Andrea de Lourdes Castillo Muñoz, mujer campesina que vive en Temuco, trabajadora en la universidad del mismo nombre de la ciudad; oriunda de Linares, por eso, siempre extraño el sol, el calor, las frutas y la flor del espino. Soy hija de Pedro e Iris, de quienes he aprendido la valentía, la transformación, la confianza, la libertad, la conversación y el amor a la tierra. Soy hermana de Pedro y Yasna, a quienes agradezco el regalo de la complicidad y el amor cuidador, cercano e incondicional; de ellos y con ellos mis sobrinos/as remolinos con vida propia, alegría de mi corazón. Estudié Teología y un Magíster en Estudios Interculturales. Fui parte de una congregación, tiempo que agradezco, vivencia necesaria que forma una fracción de mis raíces. Después de salir, mi vida dio un vuelco y, en esa evolución, siempre una respiración cerquita... un aire tenue, cálido, respetuoso: Jesús. Me considero mestiza, cuestión que pude mirar cuando me encontré con el pueblo mapuche; desde ahí pude no perder de vista de dónde vengo, cuáles son mis raíces; sin duda soy mezcla, así como la mayoría de los/as chilenos/as:

Chile, y el territorio latinoamericano al cual pertenece, es fruto de una singular gestación: la de ser producto de un cruce de sangres y símbolos. Parición de un nuevo ente que porta en sí mismo, simultáneamente, elementos de la cultura 
indígena, de la cultura europea, y a veces africana. ${ }^{11}$

Soy más que el decreto de chilenidad que buscó invisibilizar nuestra identidad en una sola."

Imaginar un telar y el movimiento de las lanas es la metodología de trabajo. Se cuenta con el acercamiento directo entre las implicadas en el estudio, en el cual se involucran necesariamente las complejidades de sus biografías, cuestión propia del método biográfi$\mathrm{Co}^{12}$, comprendiendo la narración como una técnica de tejido o costura que rompe el sentido común, no solo del lenguaje que se emplea, sino también en el cómo se "tejen y entrejen" los saberes. ${ }^{13} \mathrm{El}$ análisis será narratológico; siguiendo la hermenéutica pluritópica, se hará interpretación desde los distintos lugares de enunciación. ${ }^{14}$

Se decidió optar por el concepto indígenas y no mapuche, porque esto permite sintonizar o hermanar con las experiencias de tantas mujeres de otros pueblos de Abya Yala $^{15}$ y mestizas,

11 Sonia Montecino, Sangres cruzadas: mujeres chilenas y mestizaje (Chile: SERNAM, 1993), 13.

12 Manuel Canales, Metodologías de la investigación social (Santiago: LOM, 2006).

13 Renato Ortiz, Taquigrafiando lo social (Argentina: Siglo Veintiuno, 2004): 12-14.

14 Antonio Moreno, El Aro y la Trama (Caracas: Episteme, Modernidad, CIP, 1995).

15 La expresión Abya Yala ha sido empleada por los pueblos originarios del continente para autodesignarse, en oposición a la expresión dado que es la autodefinición más cercana a la realidad histórica de las féminas del territorio llamado Chile. Se habla y se sitúa desde esta actitud de respeto y valor de las experiencias espirituales tan diversas e inagotables. Por último, se decide referir a las espiritualidades, pues es el movimiento de arriba, abajo, adentro, afuera, que sostiene la vida del ser humano y es justamente este el que queremos "aparezca y desaparezca" en el escrito; además, porque espiritualidades, y no religiones, serían la noción que más se acerca a la vivencia y promoción de la vida de las mujeres.

\section{Kalufsha ${ }^{16}$}

El telar necesita cuestiones fundamentales para llegar a ser telar: esto son las lanas con sus diversos colores, grosores y procedencia.

Vemos que en el tejido de las espiritualidades hay lanas muy delgadas, las cuales nos han espigado a figuras complejas, casi a punto de romperse, 10 que ha llevado, en más de una ocasión, a anudar para evitar la desintegración del tejido. Por ejemplo, en el nivel del Estado, según el trabajo sobre la caracterización de las mujeres de pueblos

\footnotetext{
"América" (Enciclopedia Latinoamericana, 2016).

16 Palabra en mapudungun que significa 'lana', sea esta de oveja, conejo o llama.
} 
indígenas de Chile ${ }^{17}$, se abordan aspectos demográficos, mujeres trabajadoras y no trabajadoras, ingreso que reciben, pobreza, salud y educación, dejando fuera la dimensión espiritual. ¿Por qué se deja fuera? Si las propias mujeres demandan, desde su autonomía física, política y económica, cuestiones que tienen que ver con su espiritualidad, como son entrega de placenta; difusión y recuperación de prácticas culturales; reconocer el trabajo de cuidado que hacen. ¿Es acaso una decisión tomada por las mismas mujeres o una intencionalidad del Estado? Cabe señalar que este aspecto no solo está ajeno para los pueblos indígenas, cuestión gravitante de su ser, sino también en la mayoría de los estudios de la población chilena y de Latinoamérica. De acuerdo con lo revisado en los feminismos latinoamericanos y su relación con el Estado, vemos que la temática de la espiritualidad no está entre los planes o políticas públicas sobre género. La agenda temática versaría en "...la conducción del desarrollo económico, social y tecnológico en función de los valores recién conquistados de equidad social, pluriversalidad democrática, cohesión territorial, sustentabilidad, ética, y ampliación y profundización de la democracia y de la participación política". ${ }^{18}$

17 Claudia Echeverría, Mujeres de Pueblos Indigenas en Chile. Sistematización de algunos elementos (Gobierno de Chile: Ministerio de la Mujer y la Equidad de Género, 2017).

18 Marlise Matos y Clarisse Paradis, "Los feminismos latinoamericanos y su compleja relación con
El Estado no es neutral respecto al género ni tampoco en cuanto a lo espiritual. La necesidad de implementar la variable espiritual de las mujeres, junto a otras como clase y etnia, es una deuda pendiente.

En el estudio de género, usando la categoría de interseccionalidad, sabemos que el aspecto religioso (o creencias) forma parte del sistema dominador patriarcal, que puede ser opresor y poco liberador ${ }^{19}$. Esto se ha fortalecido por medio de las escuelas y las iglesias: "las Iglesias cristianas, a través de sus enseñanzas, en gran manera han inculcado la sumisión de las mujeres a los varones". ${ }^{20}$ Es un deber la respuesta a la urgencia del derecho que tienen las personas sobre su espiritualidad, como bien indica la razón de ser del Ministerio de la Mujer y la Equidad de Género, párrafo 1, art. 3, letra q. "Fomentar medidas en favor de las mujeres que reconozcan y resguarden la multiculturalidad y las identidades étnicas, respetando sus propias visiones, prácticas, necesidades y creencias, en armonía con los derechos humanos" ${ }^{21}$, o como

el Estado: debates actuales", Íconos - Revista de Ciencias Sociales 45 (2012): 94.

19 Javiera Cubillos, "La Importancia de la Interseccionalidad para la Investigación Feminista", Oximora Revista Internacional de Ética y Política 7 (2015): 123.

20 Vicenta Mamani, Identidad y espiritualidad de la Mujer Aymara. (Cochabamba: Itinerarios, 2014): 127.

21 Claudia Echeverría, Mujeres de Pueblos Indígenas en Chile. Sistematización de algunos 
solicita la ONU en su Declaración sobre los Derechos de los Pueblos Indígenas:

Los pueblos indígenas tienen derecho a practicar y revitalizar sus tradiciones y costumbres culturales. Ello incluye el derecho a mantener, proteger y desarrollar las manifestaciones pasadas, presentes y futuras de sus culturas, como por ejemplo, lugares arqueológicos e históricos, artefactos, diseños, ceremonias, tecnologías, artes gráficas y dramáticas y literaturas, así como el derecho a la restitución de los bienes culturales, intelectuales, religiosos $\mathrm{y}$ espirituales de que han sido privados sin su consentimiento libre e informado o en violación de sus leyes, tradiciones y costumbres. ${ }^{22}$

Hay claridad de que un elemento identificador en la constitución de la identidad de las mujeres indígenas es lo espiritual, como es el caso de las mujeres mapuche en el sur, "El feyentun es el creer, el tener convicción del ser mapuche, es lo que moviliza al mapuche en su espiritualidad mapuche" 23 , o de las mujeres colla en el norte de Chile, "mujer Colla es la tierra y que independientemente que tengamos o no (...) yo creo que es lo unido a la tierra es la unión espiritual si se puede decir a la

elementos, 32.

22 ONU. Ver_Declaración sobre Derechos de los Pueblos indígenas, art.3. (2008).

23 Ximena Painemal, "Identidad y Espiritualidad Mapuche: la visión del Machi” (tesis para optar al título de Psicóloga, Universidad ARSIS Chile, 2011): 91 . tierra esa es la fortaleza que tiene" 24 . Dicho de otra manera, la espiritualidad "es la fuerza que está con la persona, lo que motiva, promueve el pensamiento, la razón de existir así como entender las realidades diversas que hoy día han surgido" 25 . Visto así, es necesario poner atención en esta dimensión, desde las diversas disciplinas, en los niveles eclesial y estatal, respondiendo cada una al daño o muerte que ha causado a la espiritualidad.

La espiritualidad de las mujeres ha querido ser controlada, perseguida y cercada a lo largo de la historia, porque es una experiencia resistente y de vida, como alternativa de salud, organización y ritualidad donde al centro está la existencia de todas. Esta persecución se ve claramente en el libro de Silvia Federici, Calibán y la bruja, que, con el pretexto de la evangelización, castigó esa subversión y resistencia social de las mujeres, tanto en Europa como en América Latina y El Caribe: "la brujería fue una religión matrifocal en la que la Inquisición centró su atención después de la derrota de las herejías, acuciada por un nuevo

24 Viviana Rodríguez y Cory Duarte, "Experiencias y creencias de Mujeres Colla de la región de Atacama", CUHSO-CULTURA -HOMBRE -SOCIEDAD, Vol. 28,1 (2018): 42.

25 Módulo espiritualidad, conocimientos e historia de los pueblos indígenas de Abya Yala. "Manual de las y los participantes" (Bolivia: Fondo Indígena, 2008): 73. 
miedo a la desviación doctrinal"26. Las mujeres brujas fueron un peligro y clara competencia para la Iglesia, dadas sus posiciones de poder en los pueblos por cristianizar, así como sus prácticas y ritos religiosos: "Eran las grandes chamanas, conocedoras de la naturaleza y sus medicinas, sanadoras de la enfermedad física y espiritual, las parteras del mundo, y a su vez eran la fuerza capaz de conectar con la muerte y la destrucción" ${ }^{27}$. Ellas desacreditaban y resistían la conversión traída por los clérigos españoles, defendiendo su espiritualidad ancestral: "En efecto, gracias en gran medida a la resistencia de las mujeres, la antigua religión pudo ser preservada". ${ }^{28}$

La religión católica se ha impuesto hace más de 500 años con un modelo de evangelización intolerante, mediante el cual la superioridad frente a las espiritualidades indígenas y el rechazo tanto de sus ritos como de autoridades religiosas han sido frecuentes; es necesario superar estas formas y avanzar en un diálogo interreligioso o interespiritualidades, un reto para la teología católica e india hoy ${ }^{29}$, más aún por la fuerza que está teniendo el fun-

26 Silvia Federici, Calibán y la bruja. Mujeres, cuerpo y acumulación originaria. (Traficantes de Sueños, 2010), 247.

27 Marcela Bohórquez, "Brujas contemporáneas: entre mundos y devenires espirituales", 148.

28 Silvia Federici, Calibán y la bruja. Mujeres, cuerpo y acumulación originaria, 307.

29 Cristian Muñoz, Religiosidad e Indigenismo. Ensayo desde la Etnoeducación Crítica en nuestro damentalismo ${ }^{30}$ católico y evangélico, que sataniza cualquier otra forma que no sea la propia.

Frei Betto, teólogo católico, reflexiona sobre la clara diferencia entre espiritualidad y religión. Dice que la primera existe desde que irrumpe el ser humano, sin embargo, las religiones son recientes (unos 8000 años):

Las religiones en principio, debieran ser fuentes y expresiones de espiritualidades. Pero no siempre sucede así. En general, la religión se presenta como un catálogo de reglas, creencias y prohibiciones, en tanto que la espiritualidad es libre y creativa... la religión es una institución; la espiritualidad una vivencia. $^{31}$

Se ve una diferencia que hasta podría permitir una colisión entre una concepción y otra. Para el autor, siendo

continente (Abya Yala). (Valparaíso-Chile: LOM, 2017).

30 "El fundamentalismo no es una doctrina, es una manera de leer e interpretar las doctrinas, de entender 'mi doctrina' o 'mi verdad' como la única verdadera, porque todas las demás están erradas. Por el hecho de que no son verdaderas, pueden ser denunciadas, perseguidas y pueden ser destruidas, porque el error no tiene ningún derecho. Ahí está la base del profundo desentendimiento, del ánimo belicoso contra las demás creencias religiosas". Marcelo Barros, El ventarrón divino en los remolinos de la liberación. En Iglesia que camina con espiritu y desde los pobres (Uruguay: Amerindia, 2016), 24.

31 Frei Betto (2011). Espiritualidad y religión. https://www.alainet.org/es/active/51490 (Consultada el 26 enero de 2019). 
distintas, se complementarían, pese a que en la realidad no sea así; al contrario, las reglas religiosas han llevado a separar los buenos de los malos, el pecado de la gracia, la razón o idea de Dios frente al corazón o a la vivencia de lo espiritual. Jesús rompe con la religión de su tiempo y vive una espiritualidad centrada en amor, comunidad, justicia, defensa, sanación y caminar con los/as pobres.

Desde la filosofía intercultural, una mirada sobre la espiritualidad sería

la que se expresa en el ser humano como la fuerza de transcendentalidad que lo motiva a manifestarse contra el encarcelamiento de la vida en las redes y trampas en que con tanta astucia y variedad de máscaras ha sabido "enredarla" ese otro "espíritu" que desde Comte llamamos "positivo". 32

Estaríamos hablando de una fuerza que trasciende y supera el saber científico, dando paso a otras sensibilidades y sabidurías.

Desde los estudios del feminismo, esta diferenciación es también elocuente; la espiritualidad sería un

32 Raúl Fornet-Betancourt, Formación, espiritualidad y universidad. (Aachen: Wissenschaftsverlag Mainz, 2018): 23. conjunto de acciones y sentimientos que surgen en relación con concepciones sobre lo sagrado, no necesariamente unido a una comunidad religiosa o culto. En cambio, la religión es definida por algunos autores como la obligación con una organización o tradición particular de fe, o también como el intento de codificar las experiencias espirituales dentro de un sistema. Mientras la espiritualidad nos conduce a hacernos preguntas sobre el sentido y el propósito de la vida y no tiene por qué estar limitada a ningún tipo de creencias o prácticas en particular, la religión se define como la creencia en la existencia de un poder reinante sobrenatural, creador y controlador del universo, de manera que la religiosidad sería el grado en que se cree, se sigue y se practica una religión. ${ }^{33}$

Más allá de que estén enemistadas ambas concepciones, para los estudios feministas, será la espiritualidad la que mejor dé cuenta de la vivencia profunda de sentido que experimentan las mujeres y la religión se definirá como aquel sistema androcéntrico y patriarcal, del cual hay que liberarse por su opresión sistemática.

33 Angie Simonis, "La Diosa y el poder de las mujeres. Reflexiones sobre la espiritualidad femenina en el siglo XXI", Feminismo/s Revista del centro de Estudios sobre la Mujer de la Universidad de Alicante 20 (2012): 10. 


\section{Zuẅ̈we $e^{34}$}

Hasta aquí, tenemos el telar y las lanas, pero no son nada sin el movimiento que les dará una realidad, diseño, dibujo único. Mucho depende de este movimiento de las lanas, que cruza entre las hebras construyendo, renovando, avanzando, atravesando y presentando diferentes realidades. Nosotras hemos tejido nuestra espiritualidad como mujeres mapuche y mestiza.

\section{Pérsida:}

¿Cómo he logrado vivir mi espiritualidad siendo mujer, dirigente, madre $\mathrm{y}$, a su vez, mapuche o indígena? Lo fundamental es que no debe haber una ruptura en la raíz, a esto me refiero con que desde que naces tienes una forma de vida que te van guiando; luego, te desarrollas $\mathrm{y}$, posteriormente, comienzas a indagar las diferentes ideas, inicia la curiosidad del conocer, del sentir espiritual y en esta curiosidad está la de las creencias distintas a la tuya. Con las imposiciones del feyentun foránea (católica, evangélica, etc.), que pretenden impregnar en nuestro ser, me pregunto: ¡¿Por qué y cómo pueden castigar el mapuche kimün ${ }^{35}$, nuestro

34 Palabra en mapudungun que indica el movimiento realizado por las lanas en el telar cuando se entrecruzan.

35 En mapudungun, hace alusión al conocimiento ancestral acumulado con el paso de las generaciones y codificado lingüísticamente (Becerra y Llanquinao, 2017). idioma, nuestra feyentun?! Hay muchas personas que transitan al interior de otras iglesias, pero lo que en la práctica nuevamente retomamos o vivimos es nuestra propia espiritualidad, nuestra raíz.

Lo espiritual es lo que me ha permitido fortalecer mi propio feyentun $\mathrm{e}$ ir tejiendo este eslabón fundamental. No es fácil escribir o decir en palabras el sentir desde nuestro piuke $e^{36}$; es una fuerza invisible, intangible, que cada persona acepta y trata de llevar a la práctica con la fuerza espiritual que nos inculcan, nos heredan nuestros fütake che ${ }^{37} \mathrm{y}$ es como bien lo expresan los Aymaras: "el alimento de nuestros vidas, la llevamos en lo más profundo de nuestros ser, es el eje que integra y vitaliza toda nuestra existencia" ${ }^{\prime 3}$.

Jesús fue un hombre político y espiritual adaptado a la cultura; sin embargo, hoy, por tantas reglas e intervenciones, lo han divido. Yo creo que el Jesús de antes era ajustable a la vida cotidiana, a la vida del ser; en el presente, se le ve como un Jesús divido, quebrado y lejano. Yo opino que Jesús no era machista; no obstante, la Iglesia lo es, a mí me han cuestionado como mamá soltera... no puedo estar ahí, te

36 Palabra en mapudungun que indica el corazón.

37 En mapudungun, hace alusión a personas mayores (Becerra y Llanquinao, 2017, 120).

38 Vicenta Mamani, Identidad y espiritualidad de la Mujer Aymara, 137. 
juzgan tu libertad, te condicionan, te limitan, por ejemplo, a no llevar un grupo adelante solo por ser madre soltera. Yo creo en la dualidad, pero, si el hombre no está, se debe enseñar no más, se le debe dar cabida a la mujer que sea. Nosotros/as seremos pobres, mas, en nuestra identidad, existe el respeto, eres considerado/a, valorado/a; nuestro che $e^{39}$ no desprecia a nadie por el simple hecho de ser persona.

Mi propuesta es un cambio constitucional, con la cual el Estado considere el real diálogo y la persona blanca acepte convivir con el pensamiento de los pueblos, para adaptarse al respeto de la biodiversidad espiritual de estos. Hasta hoy nos han considerado como una piedra de tropiezo en su existencia; no aceptan el diálogo, no permiten que las poblaciones se desarrollen con su identidad y autoestima tanto en lo político como espiritual. Me identifico en este ámbito, por la razón de que siento que en nuestra cultura mapuche tenemos una constante amenaza y lucha por mantener viva nuestra espiritualidad, porque hoy está débil y dañada, como ocurre, por ejemplo, también, con el pueblo aymara: "las mujeres vivimos con una espiritualidad vulnerable, llena de inseguridades" ${ }^{40}$ que

39 En mapudungun, significa hombre, personas o gente en general (Becerra y Llanquinao, 2017, 92).

40 Vicenta Mamani, Identidad y espiritualidad de la Mujer Aymara, 128. debemos transformar. Nosotros/as mapuches, constantemente, estamos sufriendo diferentes cambios, sean políticos, económicos, sociales, culturales o espirituales, estos últimos con frecuencia intimidados por creencias foráneas.

\section{Andrea:}

Sin duda es otra relación la que he vivido conmigo misma, con los/ as demás y con Jesús, al momento de no seguir en la vida religiosa. He sabido mucho más del silencio, conversación, complicidad, nervios, llanto y paz que todos mis años de vida. Ha sido un tiempo intenso de novedad tan amplia como el mar. Siento que encontré un lugar y una experiencia con la vida, donde muchas veces no hay respuestas, no se sabe qué hacer o cómo hacerlo; he aprendido a conocer y a amar a la intemperie. Digo intemperie, empezando por no ir a ningún templo, seguidora sin casa, sin ritos, sin sacramentos, sin comunidad de hermanos/ as, sin eucaristía, sin mes de María... no tengo nada de lo que un día tuve. Intemperie donde se reconoce vientecito, frío, lluvia, tibieza de lo nuevo. Considero que estaba medio asfixiada, que, aunque había intentos de "la manera de Jesús", no resultaban; yo no digo que hoy viva esa manera, pero siento mis alas, disfruto el vuelo, me percibo más viva y honda. En toda la vivencia, mi encuentro con el pueblo mapuche ha sido fundamental, no solo porque 
me ha llevado a saber de dónde vengo, sino porque me ha permitido descubrir que ese encuentro, dialogo y amor con lo totalmente diferente es posible y dignificante.

La espiritualidad de vaivenes, como la vida, dice mucho de la experiencia del encuentro necesario y verdadero con las otras formas de creer, sentir, ver, sufrir, amar. Nos pone en el movimiento común de la transformación, necesidad y confianza que vivimos las personas. Es una espiritualidad de la existencia, asumiendo lo que nos aflige, mata, duele, enferma, condiciona, confunde, molesta... tantas veces sin respuestas; más bien se da un estar "ahí" en la fragilidad, a la intemperie.

Eliana Valzura, al hablar de espiritualidad de intemperie, afirma que es necesario primero dejar en claro la espiritualidad exterior o del templo, la que vendría a ser ritos, liturgias, ornamentos y lugar "sagrado" (donde se practica y el que es indicador de que fuera de él no es posible otra modalidad o, si se da, no sería válida). Este tipo de espiritualidad sería propia de las religiones que en vez de liberar oprimen y en vez de dialogar con otros estilos los excluyen o discriminan. Buscan la seguridad en las reglas, formas, ideas o certezas.

La espiritualidad o desespiritualidad de intemperie va a contramarcha de estas espiritualidades y se niega a someterse a ellas para sentir el amparo, aunque sea, de algo frente a la incertidumbre vital más angustiante: estar vivos en este mundo sin saber hasta cuándo ni de qué forma y sin tener ninguna certeza sobre lo que nos espera. La desespiritualidad no busca subir, busca entrar y bajar a la profundidad del ser. En lugar de llegar alto desea cavar más y más profundamente. Su ideal no es divinizarse, sino humanizarse. Porque su ejemplo es Jesús. Convertir el corazón de piedra en corazón de carne es una de las consecuencias que primero se observan. ${ }^{41}$

Es posible una espiritualidad, entonces, en la cual otras formas son posibles y, sobre todo, ponen en movimiento hacia fuera, hacia lo/as demás, hacia lo profundo de una misma y de las otras personas. Es necesario este tipo de espiritualidad que es humanización, que se acomoda y se alegra por la vida del otro/otra tal cual.

\section{Chapil $^{42}$}

Queriendo que el tejido no se desarme, compartiremos unos amarres finales.

41 Eliana Valzura, Apuntes sobre espiritualidad. (2017) https://teologiadeintemperie.wordpress. com/2017/07/09/apuntes-sobre-espiritualidad/. (Consultada el 12 diciembre de 2018).

42 Palabra en mapudungun que significa amarre final del tejido realizado en el telar. 
Amarre uno: Constatamos la importancia y el reconocimiento de la espiritualidad de las mujeres, entendida esta como "una cualidad más allá de la afiliación religiosa, apunta hacia el respeto y amor por la naturaleza y la humanidad, y la búsqueda de la armonía con el Universo"43; es decir, aquella que nos abre y moviliza más allá de la razón y de nosotras mismas, llevándonos a la convivencia y al equilibrio con todo lo creado. Es necesario no cortar el tejido de la espiritualidad que cada quien va viviendo: mirar su dibujo, animarse a crear otros, ahondando en las espiritualidades más que en las religiones.

Amarre dos: La espiritualidad es como un hilo de oro fundamental para entrar en diálogo, especialmente con los pueblos indígenas, en nuestro caso, con el pueblo mapuche. Para ello, tanto el/la winka ${ }^{44}$ como el/la mapuche deben hacerlo desde su conciencia espiritual, desde su ser espiritual. El desafío, desde aquí, es cuidar y cultivar la espiritualidad, ya que es un gran instrumento para mantener y recrear la identidad de los pueblos.

Amarre tres: Lo decolonial ${ }^{45}$ es poner en evidencia la colonización e ir

43 Angie Simonis, "La Diosa y el poder de las mujeres. Reflexiones sobre la espiritualidad femenina en el siglo XXI", 10.

44 Palabra en mapudungun que alude a la persona no mapuche.

45 Entendemos lo decolonial como lo plantea Catherine Walsh, esto es, aquello que "encuentra en contra de los poderes coloniales y de cómo se configuran las estructuras de poder. Desde nuestra reflexión, nos desafía a cuestionar y enfrentar al patriarcado eclesiástico, como aquella forma que ha silenciado las espiritualidades de las mujeres a lo largo de la historia. Sabemos que estos silenciamientos y relaciones coloniales no han desparecido, que están vivos e invisibilizados.

Amarre cuatro: La interculturalidad es una actitud y práctica de reconocimiento desde quienes han sido excluidas/os. Por lo tanto, no podemos quedarnos en un discurso de buena convivencia y diálogo; debemos encaminarnos, con paso firme, hacia la justicia epistémica, es decir, dejar de hablar por los otras/os e interpretar sus experiencias: "no es posible hablar del indio, de las relaciones con éste, o con el otro y otra en general, sin él ni ella; sin su voz en primera persona" ${ }^{\prime 6}$. Esto es un descentrarse del lugar de donde se piensa, escribe o siente, validando otras formas de decir, pensar, sentir,

su razón en los esfuerzos de confrontar desde "lo propio" y desde lógicas - otras y pensamientos - "otros" a la deshumanización, el racismo y la racialización, y la negación y destrucción de los campos - otros del saber" (Catherine Walsh, 2005: 24), evidenciando un orden dominante impuesto por el poder colonial.

46 Lorena Zuchel y Héctor Samour, "Para una interculturalidad critica. Reflexiones desde Raúl Fornet Betancourt e Ignacio Ellacuría”, HYBRIS. Revista de Filosofia, Vol. $9 \mathrm{~N}^{\circ}$ Especial: Debates contemporáneos sobre Justicia Social (julio 2018): 94. 
narrar; apostando por un lenguaje no universal, sino diverso.

Amarre cinco: Se trataría de encontrarnos en la novedad del no saber, con una actitud flexible, sin apuros, viviendo de ensayo y error, porque corazonar desde la espiritualidad es asumir lo "incompleto, borroneado, tembloroso, asistémico". Ello consiste en un ideal para quienes queremos más preguntas que repuestas, más escucha que hablar, más "muchas verdades" que "única verdad", más liberar que dominar; parecido a Jesús, siempre desafinando, desafiando, desordenando para volver al equilibrio. ${ }^{47}$

Amarre seis: Creemos que para avanzar en un encuentro y diálogo interespiritualidades, entre mujeres católicas e indígenas, es necesario hacerlo desde las espiritualidades, volviendo a un estilo de vida y compartir desprovisto de recetas y expectativas. En este sentido, la espiritualidad de la intemperie nos puede ayudar; es una de las lanas o el lenguaje que nos posibilita encontrarnos como mujeres diversas.

Remache de nuestro tejido:

"la etnicidad desde el punto de vista de las mujeres, podría compararse más bien con un tejido, por su naturaleza intercultural. En el tejido las mujeres incorporan lo ajeno para domesticarlo, para suavizarlo, y éste es el acto femenino por excelencia" (Rivera, 2015, 68).

\section{Bibliografía}

Allione, Tsultrim. 2016. Mujeres de sabiduría. Barcelona: Ediciones La liebre de marzo.

Barros, Marcelo. 2016. El ventarrón divino en los remolinos de la liberación. En Iglesia que camina con espiritu y desde los pobres. Uruguay: Amerindia.

Becerra, Rodrigo y Llanquinao, Gabriel, editores. 2017. Mapun kimün. Relaciones mapunche entre persona, tiempo y espacio. Santiago, Chile: Ocho Libros.

Betto, Frei. 2011. Espiritualidad y religión. https://www.alainet.org/es/active/51490. (Consultada el 26 enero de 2019).

Bohórquez, Marcela. 2019. Brujas contemporáneas: entre mundos y devenires espirituales. Revista NÓMADAS, n. ${ }^{\circ}$ 50: 137-153.

Canales, Manuel. 2006. Metodologías de la investigación social. Santiago, Chile: LOM.

Cubillos, Javiera. 2015. La Importancia de la Interseccionalidad para la Investigación Feminista. Oxímora Revista Internacional de Ética y Política, núm. 7: 123. 
Echeverría, Claudia. 2017. Mujeres de Pueblos Indigenas en Chile. Sistematización de algunos elementos. Ministerio de la Mujer y la Equidad de Género. Gobierno de Chile.

Enciclopedia Latinoamericana. Ver Abya Yala. http://atinoamericana. wiki.br/es/entradas/a/abya-yala. (Consultada el 5 de abril de 2020).

Federici, Silvia. 2010. Calibán y la bruja. Mujeres, cuerpo y acumulación originaria. Traficantes de Sueños.

Fornet Betancourt, Raúl. 2001. Transformación intercultural de la filosofía. Barcelona: Desclée de Brouwer.

. 2018. Formación, espiritualidad y universidad. Aachen, Alemania: Wissenschaftsverlag Mainz.

Grosfoguel, Ramón. 2006. La descolonización de la economía política y los estudios postcoloniales. Transmodernidad, pensamiento fronterizo y colonialidad global. Tabula Rasa, 4: 17-48.

Mamani, Vicenta. 2014. Identidad y espiritualidad de la Mujer Aymara. Cochabamba, Bolivia: Itinerarios.

Maldonado, Nelson. 2007. "Sobre la colonialidad del ser: contribuciones al desarrollo de un concepto", en: El giro decolonial. Reflexiones para una diversidad epistémica más allá del capitalismo global, eds. Santiago Castro-Gómez y Ramón Grosfoguel, 127-167. Bogotá: Lesco Pensar-Siglo del Hombre editores.

Matos, Marlise y Paradis, Clarisse. 2012. Los feminismos latinoamericanos y su compleja relación con el Estado: debates actuales. Íconos. Revista de Ciencias Sociales, núm. 45: 91-107.

Módulo espiritualidad, conocimientos e historia de los pueblos indígenas de Abya Yala. 2008. Manual de las y los participantes. Bolivia: Fondo Indígena.

Montecino, Sonia. 1993. Sangres cruzadas: mujeres chilenas y mestizaje. Chile: SERNAM.

Moreno, Antonio. 1995. El Aro y la Trama. Caracas: Episteme, Modernidad, CIP.

Muñoz, Cristian. 2017. Religiosidad e Indigenismo. Ensayo desde la Etnoeducación Crítica en nuestro continente (Abya Yala). Valparaíso-Chile: LOM.

Painemal, Ximena. 2011. Identidad y Espiritualidad Mapuche: la visión del Machi. Tesis para optar el título de Psicóloga, Universidad ARSIS Chile.

ONU. 2008. Art. Declaración ONU sobre Derechos de los Pueblos indígenas. 
Ortiz, Renato. 2004. Taquigrafiando lo social. Argentina: Siglo Veintiuno.

Rodríguez, Viviana y Duarte, Cory. 2018. Experiencias y creencias de Mujeres Colla de la región de Atacama. CUHSO-CULTURAHOMBRE-SOCIEDAD, vol. 28, 1: 34-54.

Rivera, Silvia. 2015. Violencia e interculturalidad. Paradojas de la etnicidad de la Bolivia de hoy. Revista Telar, 15.

Simonis, Angie. 2012. La Diosa y el poder de las mujeres. Reflexiones sobre la espiritualidad femenina en el siglo XXI. Feminismo/s Revista del centro de Estudios sobre la Mujer de la Universidad de Alicante, 20: 10.
Valzura, Eliana. 2017. Apuntes sobre espiritualidad. https://teologiadeintemperie.wordpress.com/2017/07/09/ apuntes-sobre-espiritualidad/. (Consultada el 12 diciembre de 2018).

Walsh, Catherine. 2005. (Re)pensamiento crítico y (de)colonialidad. En: Catherine Walsh (edit.), Pensamiento crítico y matriz (de)colonial, reflexiones latinoamericanas, ed. citada, 13-35.

Zuchel, Lorena y Samour, Héctor. 2018. Para una interculturalidad crítica. Reflexiones desde Raúl Fornet Betancourt e Ignacio Ellacuría. HYBRIS. Revista de Filosofía, vol. 9, n. ${ }^{\circ}$ Especial: Debates contemporáneos sobre Justicia Social. ISSN 07188382, pp. 75-98, julio. 
